\title{
THE BONE MARROW IN HUTCHISON'S SYNDROME
}

\author{
BY \\ A. PINEY,* J. MALLARMÉ, $\dagger$ AND M. S. ROSS $\ddagger$
}

(RECEIVED FOR PUBLICATION MAY 2, 1950)

Since Hutchison's now classical paper "On Suprarenal Carcinoma in Children with Metastases in the Skull" appeared in 1907, the syndrome, which now bears his name, has frequently been observed and recorded.

The salient features are the development of malaise and some degree of pallor in a previously healthy child, followed by left-sided proptosis, due to metastases in the orbit, together with signs of other secondary deposits in the cranial bones. The primary tumour, which has the histological structure of a neuroblastoma, with more or less well-developed " rosettes," is situated in the left suprarenal gland, where it may form a mass sufficiently large to be palpable. Less commonly, pains in the bones are the presenting symptom, while, occasionally, severe anaemia is an early sign, as in the case to be recorded here.

\section{Case Report}

M. K., a girl aged $6 \frac{1}{2}$ years, complained of pain in the right thigh during April, 1949. A radiograph taken at this time is said to have shown some diffuse rarefaction of the upper third of the right femur, and the leg was therefore put in plaster. Slight, left-sided exophthalmos developed, but, as an ophthalmologist could find no abnormality other than some enlargement of tarsal glands, little attention was at first paid to this. Then the child became obviously ill, with pallor and anorexia, and was transferred to the care of one of us in Paris (September, 1949).

At this time, she was a fairly well-nourished but pale child, with no detectable enlargement of the liver, spleen, or glands, but with fairly severe left-sided proptosis. There were no complaints of pain, and no tenderness of any of the bones could be detected.

The blood picture was that of a simple hypochromic anaemia.

$\begin{array}{llcc}\text { Red corpuscles } & \ldots & \ldots & 2,600,000 \text { per c.mm. } \\ \text { Haemoglobin } & \ldots & \ldots & 40 \% \\ \text { Leucocytes } & \ldots & \ldots & 3,700 \text { per c.mm. } \\ \text { Neutrophils } & \ldots & \ldots & 49 \% \\ \text { Eosinophils } & \ldots & \ldots & 7 \% \\ \text { Monocytes } & \ldots & \ldots & 2 \% \\ \text { Lymphocytes } & \ldots & 42 \%\end{array}$

No abnormal red or white cells were seen.

A second blood count, a week later, showed little change, but it was stated that there were $3 \%$ leucoblasts. Unfortunately this film was not preserved.

* From St. Mary’s Hospital, Plaistow, London. † From Paris. $\quad$ From Queen Mary’s Hospital for the East End, London. 
$X$-ray examination of the skeleton revealed widespread changes.

The pelvis and upper ends of the femora (Fig. 1) showed increased density and thickening of the bony trabeculae, with complete disorganization of the normal structure. There were some clear islets and some clear bands, which ran parallel with the

Fig. 1.-Radiograph of pelvis and upper ends of femora.

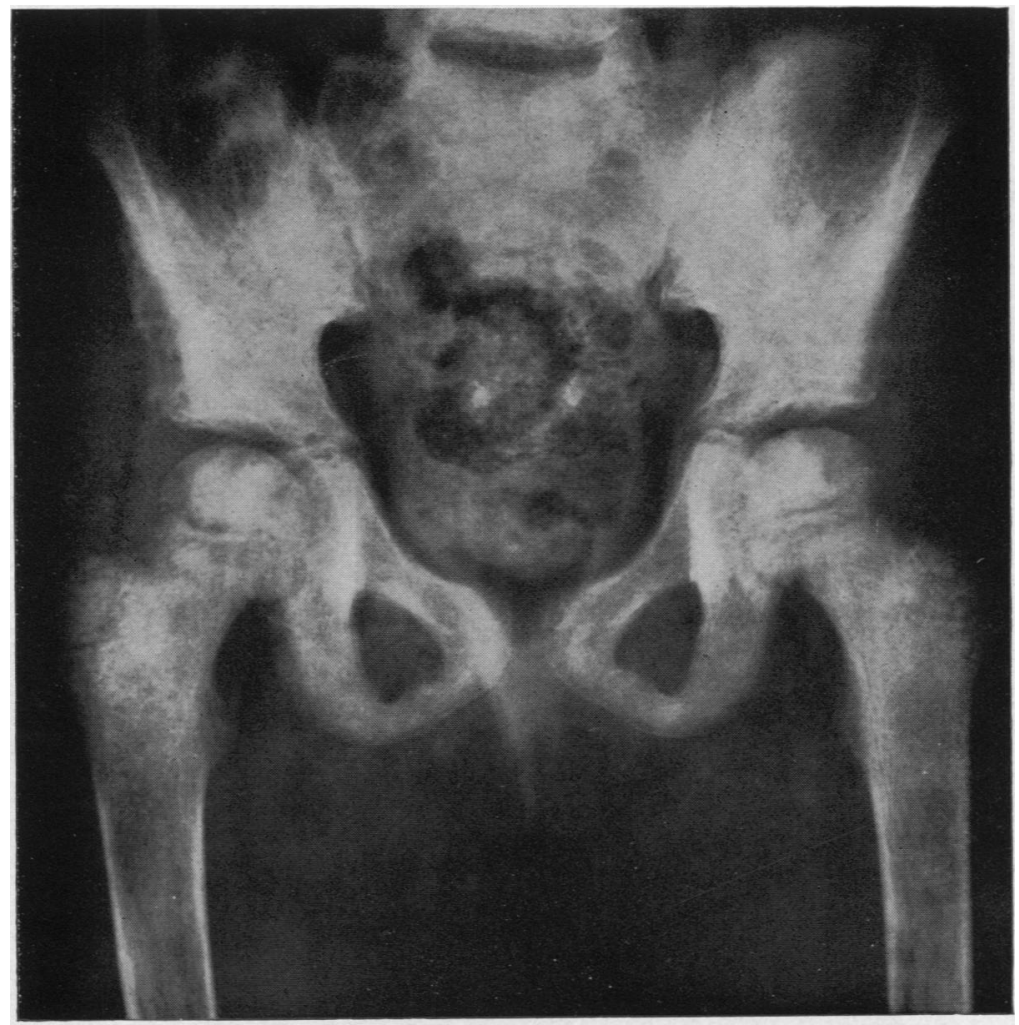

cortex and also with the epiphyseal cartilages. On the left side, the cortex of the right iliac bone seems to have been penetrated by actively growing tissue.

The cranium (Fig. 2) showed the presence of very small clear islets, more or less round in outline, but sometimes confluent. These were most numerous near the vertex but were scattered throughout the cranial vault. There was also dense opacity of the left maxillary sinus together with disappearance of the floor of the left orbit.

A sternal puncture was performed on September 17, 1949. Very little haemopoietic tissue was obtained, but the material was highly cellular, the overwhelming majority of the cells being of approximately the same type. They were reported as follows:

" Reticular cells, almost all undifferentiated, except for a few of leucoblastic type. Diagnosis : reticulo-leucosarcomatosis."

More detailed examination showed that the cells were not, in fact, all exactly alike. The majority were large, with finely stippled nuclei and very indistinct cytoplasmic outlines so that, where the cells lay close together, there was a syncytial appearance. In a few of the nuclei, a vacuole with a central dot of chromatin could be seen. 


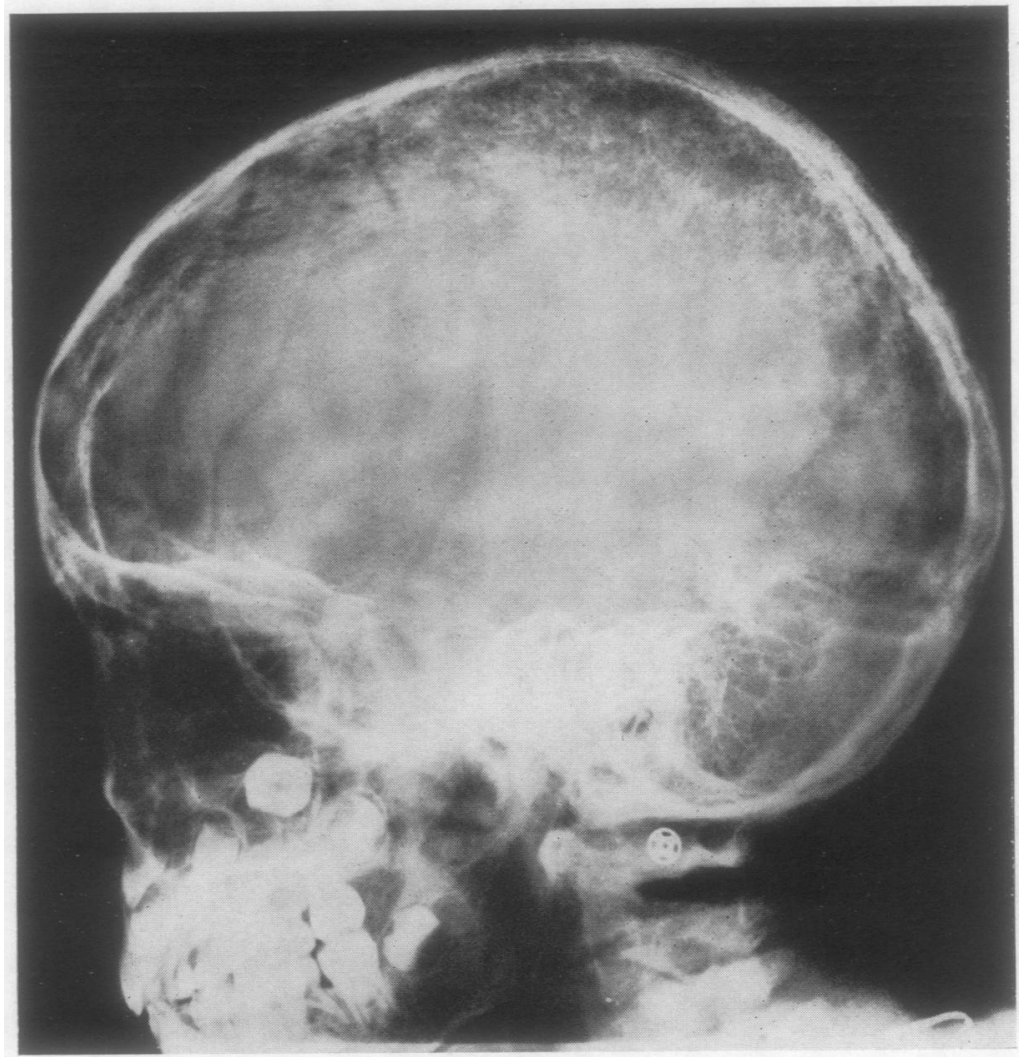

Fig. 2.-Radiograph of skull showing diffuse pilzähnliche Metastasenbildung.

In addition, a number of extremely degenerate elements were found, usually at the periphery of the masses (Fig. 3).

On October 8, 1949, the child was in a very poor condition, there was slight fever, and well marked left-sided exophthalmos, which was said to have improved considerably as a result of radiotherapy. There was no enlargement of liver, spleen, or glands, and no masses could be palpated in the abdomen. The bones were neither painful nor tender. There were no mucosal or cutaneous haemorrhages, although the child was strikingly pale.

Fig. 3.-Drawing of a mass of cells from the marrow (16.9.49) showing the syncytial arrangement and one cell with a nuclear vacuole and several other degen. erate elements.

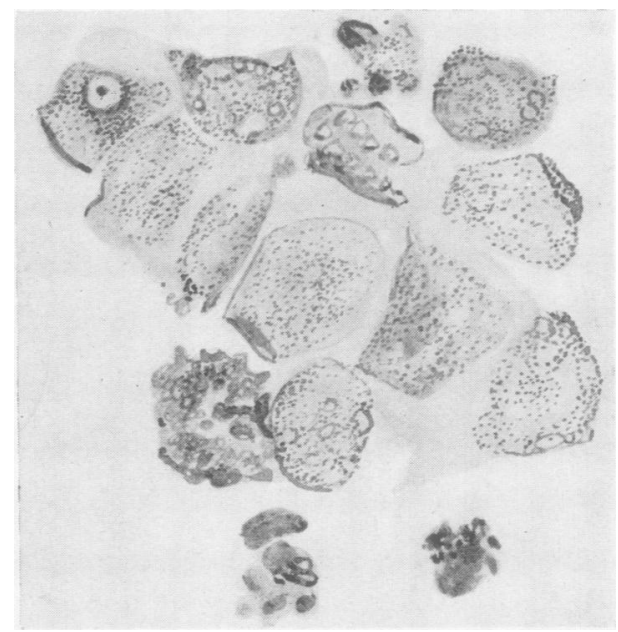


A blood count on October 22, 1949, showed:

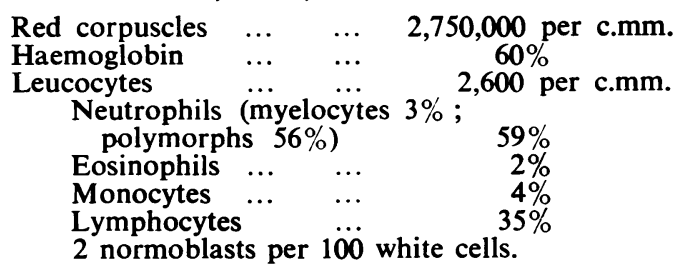

On October 23, 1949, the child was brought to England. She was now extremely ill, and the proptosis was very great.

A sternal puncture was performed, and a very remarkable picture was seen. The myelogram had the following composition:

$\begin{array}{lllr}\text { Polymorphs } & \ldots & \ldots & 24.0 \% \\ \text { Lymphocytes } & \ldots & \ldots & 2.5 \% \\ \text { Eosinophils } & \ldots & \ldots & 0.5 \% \\ \text { Reticulum cells } & \ldots & \ldots & 72.0 \% \\ \text { Normoblasts } & \ldots & \ldots & 1.0 \%\end{array}$

The reticulum cells occurred in large sheets and greatly predominated. Some of these cells showed active phagocytosis of leucocytes and red corpuscles (Fig. 4).

Fig. 4.-Phagocytic cells from marrow film: on the left a cell containing an ingested red corpuscle in its cytoplasm, and on the right one containing a degenerate polymorph.

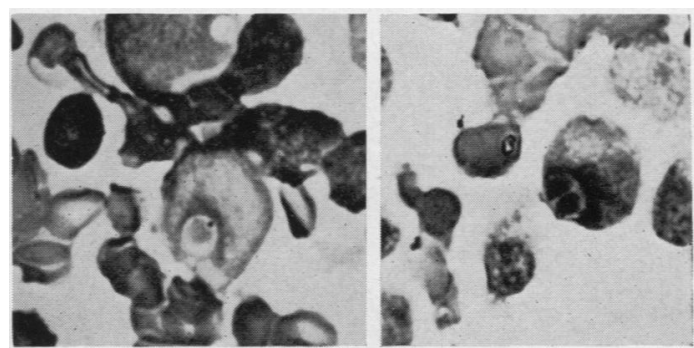

The abnormal cells found in the marrow did not all present the same type of arrangement. Thus, there were groups of cells in which the individual elements were so closely packed that individual cell-boundaries could not be distinguished. Secondly, there were some more or less isolated cells with slightly stippled nuclei and rather indefinite cytoplasm. Some of these contained debris, but a similar appearance was also seen in a considerable proportion of the cells forming syncytial masses.

Not all the isolated cells showed cytoplasmic inclusions. Some appeared to be rather more highly differentiated. Some had rounded nuclei while others showed elongation of the whole cell body. Finally, there was a considerable admixture of cells showing advanced degeneration with fragmentation of the nuclei.

Between October 28 and November 7, 1949, four injections of nitrogen mustard ( $5 \mathrm{mg}$. in all) were given. The exophthalmos almost disappeared, while the general condition also improved, partly, no doubt, as the result of a small transfusion.

A sternal puncture on November 28, 1949, showed the following:

$$
\begin{array}{lllr}
\text { Polymorphs } & \ldots & \ldots & 2.0 \% \\
\text { Lymphocytes } & \ldots & \ldots & 0.5 \% \\
\text { Eosinophils } & \ldots & \ldots & 0.5 \% \\
\text { Reticulum cells } & \ldots & \ldots & 96.0 \% \\
\quad \text { In mitosis } & \ldots & \ldots & 1.0 \%
\end{array}
$$

"Many of the tumour cells are markedly degenerate. Phagocytic activity is still evident, but not so marked as in the previous specimen." 
The syncytial masses were larger than those seen in the earlier films (Fig. 5), while more of the constituent cells had become somewhat elongated. Unfortunately, the amounts of marrow obtained on each occasion were very small, so that there was never enough for histological examination. In some of the areas in which the cells formed syncytial masses there was some indication of fibril formation (Fig. 6).

One attempt was made to obtain marrow by open operation on the iliac crest, but the specimen was too crushed to be of any diagnostic value.

The child went rapidly downhill, and died on December 29, 1949.

\section{Necropsy}

The findings at necropsy were as follows.

The body was that of a pale child, with extreme left-sided exophthalmos.

One slightly enlarged gland was found in the left upper cervical region, with an almost diffluent, pinkish-grey cut surface.

On the inner surface of the right ramus of the mandible there was a raised mass about $3 \mathrm{~cm}$. in diameter covered by a thin layer of "crackling" bone and containing red pulpy material.

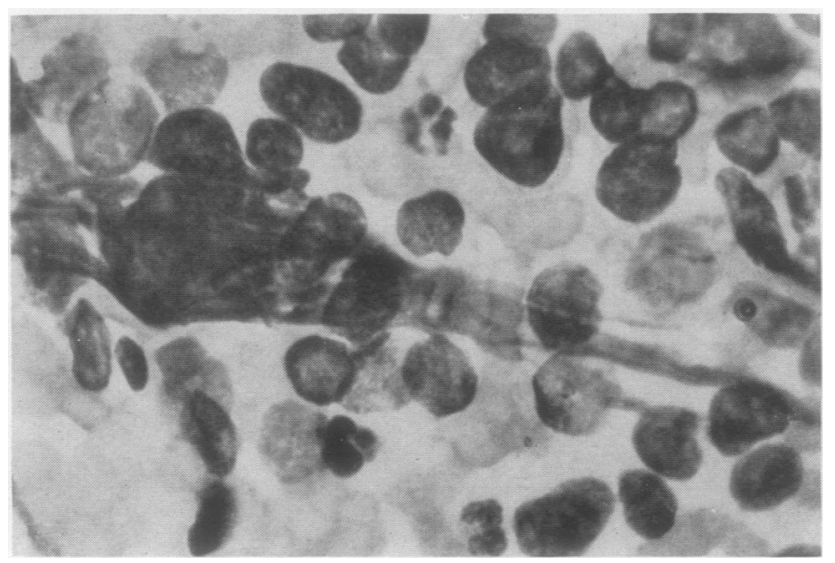

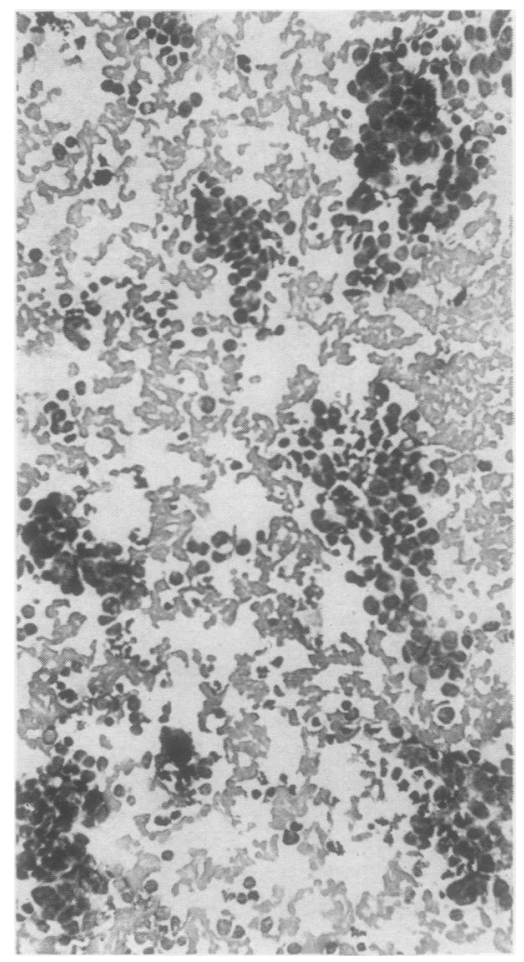

FIG. 5.-Photomicrograph of marrow film ( $\times 125)$ showing agglomeration of the abnormal cells into mosaiclike groups.

FIG. 6.-Fibrils in the substance of a syncytial mass are seen. $(\times 900$.) Cells from sternal puncture.

There was one enlarged gland adjacent to the right margin of the thymus.

In the abdomen, there was a mass, $7 \mathrm{~cm}$. in diameter, replacing the left suprarenal. This was covered with a thin capsule, and had a red, pulpy, haemorrhagic cut surface. There were several smaller similar nodules lying between the main tumour and the kidney (Fig. 7). 


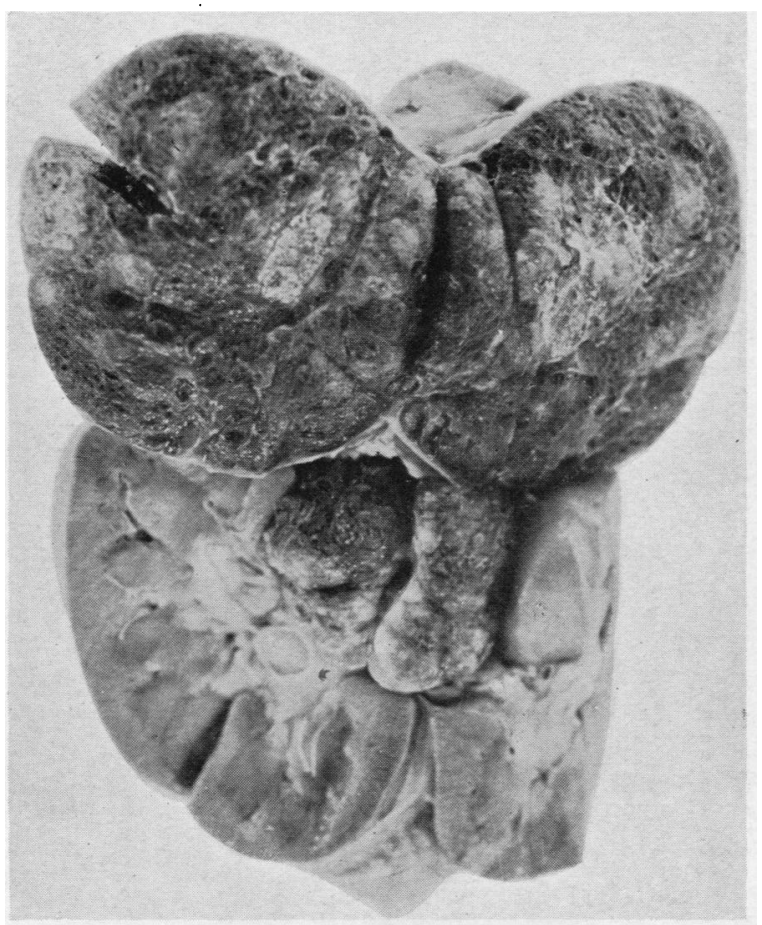

FIG. 7.-The left-sided suprarenal tumour.
The external surface of the calvarium showed a few dark areas where the cortex of the bone was extremely thin, and broke on pressure with the knife. The inner surface was covered by a sheet of plum-coloured material which had eroded the inner surface of the bone, and was adherent to the outer surface of the dura mater. There was a plum-coloured nodule situated in, and distending, the substance of the left petrous temporal bone. A large mass of haemorrhagic material filled the left orbital cavity, and was covered by a thin layer of bone in the roof of the left orbit, through which the colour of the underlying tumour was visible.

The only bones examined were the skull, sternum, vertebrae, and the left femur. These all contàined red tissue, with, in places, more deeply plum-coloured areas, where also the overlying cortex was thinned.

\section{Discussion}

The post-mortem findings made it clear that the original diagnosis of reticuloleucosarcomatosis was incorrect, and it seemed certain that this case was an example of Hutchison's syndrome, due to a neuroblastoma of the left suprarenal gland.

Histologically, this diagnosis wa $\mathrm{s}$ con fi rmed, although, as is common in these cases, the characteristic "rosettes" were not found in all the neoplastic infiltrations.

The main tumour in the lef t suprarenal gland showed sheets of darkly staining round or polygonal cells. There were also fairly large haemorrhagic areas in and near which the darkly staining cells could be seen to form

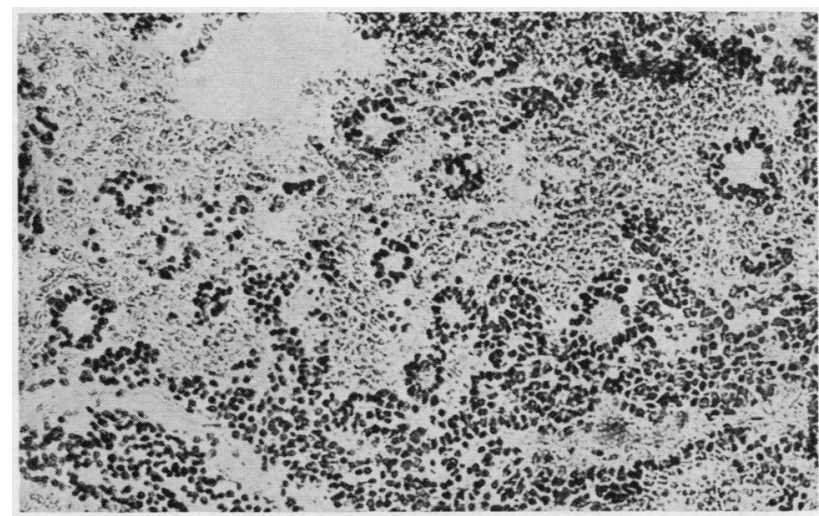

FIG. 8-Section of main suprarenal tumour showing well-marked formation of typical rosettes. $(\times 130$. 
distinct rosettes (Fig. 8). It was, in fact, almost only in the main tumour that rosettes could be recognized: elsewhere the tumour cells formed irregular trabeculae. In a few places, e.g., the mandible, tumour cells could be seen lying in vascular channels, a clear indication of the main method of spread of the growth.

Search of the literature has revealed that this case is not unique, although only a few in which the marrow has been examined during life have been recorded.

In the case of Vogel and Bassen (1939): "The normal elements of the marrow were greatly depleted. The abnormal cells were not of the haematic series. They varied in size but were generally somewhat larger than myelocytes. They occurred in clumps, and surrounding many of them was a peculiar loose greyish cytoplasm containing fibrils." There is no mention of the presence of phagocytic cells, but, in their general discussion, the authors say that "ingested debris is frequently found in the cytoplasm of the reticulum cells." No radiographs are reproduced, but it is said that there were areas of rarefaction in the skull and long bones.

The case recorded in great detail by de Weerdt (1939) was rather different, inasmuch as the primary growth was in the coccygeal body. Marrow films contained a majority of small cells, which are said to have had a nuclear structure identical with that of haemocytoblasts. There is no reference to their being collected into groups, or to the presence of phagocytic cells. In this case, as in that of Vogel and Bassen, the diagnosis of neuroblastoma was not made during life.

Kato and Wachter (1938) found "clusters of unusually immature cells relatively large in dimensions and forming syncytial masses simulating a mosaic pattern." These elements are illustrated on a coloured plate, which closely resembles Fig. 5 of the present communication. There is no reference to the presence of reticulum cells. Radiologically, there was "a granular pattern in the parietal bones" and "questionable slight diastasis of the longitudinal suture." The diagnosis was not made until necropsy, but the authors briefly refer to a second case, in which sternal puncture showed "the presence of small aggregations of neuroblasts, identical with those seen in the first case." This is probably the first record of a diagnosis of this disease having been made by marrow puncture.

The report of Hooft and Compernolle (1942) contains some descriptions which are almost completely applicable to the present case. Thus, radiologically, the skull bones showed diffusely infiltrating metastases, which are compared with the appearance one would expect from the infiltration of a fungus (pilzähnliche Metastasenbildung). Examination of Fig. 2 shows how accurate is this vivid comparison. The authors assert that it is this type of metastatic infiltration that brings about the diastasis of the sutures, but this cannot always be true, because we found the funguslike infiltrations without, however, any opening of the sutures. Similarly, the proptosis in our case was due to definite tumour-formation in the orbit, although Hooft and Compernolle attribute its occurrence to the pilzähnliche Metastasenbildung. A photomicrograph shows the mosaic-like arrangement of the tumour cells in the marrow, but no phagocytic reticulum cells are either shown or mentioned.

Albertini and Willi (1938) were among those who failed to make a diagnosis during life. But their report is of special interest, because they allege that abnormal cells, which they think were neoplastic elements, were found in the peripheral blood. In the present case, "leucoblasts" were said to have been found in the blood on one occasion, but the report of Albertini and Willi is not at all convincing, 
and certainly the photomicrographs which purport to show the tumour cells in the blood are not such as to suggest anything more than the presence of rather atypical large lymphocytes. Their description of the radiographic appearances in the skull makes use of a comparison with the damage done by moths (Mottenfrassartig), but, certainly, in the present case the appearances are much more like those of a diffuse fungoid growth. The radiographic changes in the ilium and femora appear to have been very much like those we found.

Fanconi (1943) makes the surprising statement that, in Zürich during recent years, neuroblastomatosis has been as common as leukaemia. He briefly records three cases, in one of which marrow-puncture revealed the presence of the characteristic groups of tumour cells (typische Tumorzellnester).

Patschadji (1941) recorded his observations on the radiosensitivity of neuroblastoma cells, and found it to be very great. From the present point of view, a very interesting fact is that he mentions the finding of the characteristic marrow changes in four out of his five cases. He states that the syncytia consist of large polymorphous cells with little cytoplasm, lying so closely packed that, in places, their boundaries cannot be distinguished. Radiologically, the changes in the skull were of the moth-eaten rather than the diffuse "fungus" type.

The paper by Landolt (1946) is, haematologically at least, the most important one that has been published, although it gives little clinical or radiological information. Landolt emphasizes the significance of the mosaic-like arrangement of the cells in the marrow, whereas, he states, it is never found in sarcomatous metastases. He has, however, seen a somewhat similar arrangement of cells in cases of secondary carcinoma of the marrow.

The chromatin of the neuroblastoma cells, as seen in marrow films, is very delicate, and its structure is often impossible to detect. The cytoplasm is dirty-grey, sometimes with vacuoles, and often with very indistinct boundaries. If, however, one of the cells is found lying free, the cytoplasm can be seen to form a narrow zone with fairly distinct edges. When these neoplastic cells are plentiful in the marrow, macrophages are also numerous, although, according to Landolt, this is unusual in association with other marrow metastases. It is interesting to note that the number of reticulum cells (macrophages) was found to increase considerably after a week's radiotherapy, many showing signs of active phagocytosis of tumour-cell debris.

There appears to be no doubt that the present case is one of neuroblastomatosis and that in its general features it resembles the similar cases that have been published. Even so, a point of great interest and importance emerges, inasmuch as some other authors have not mentioned the presence of any phagocytic cells in the vicinity of the neuroblastic elements in the marrow, while others, especially Landolt, have laid emphasis on their presence.

At first we were inclined to agree with Landolt's view that the neuroblastoma cells were surrounded by, and to a less extent mixed with, phagocytic reticulumcells. Admittedly, we were never able to detect any differences between the structure of the nuclei of the two types of cells, but we were inclined to attribute this failure to the extreme immaturity of the elements. We now think that most of the cells were of the same type, namely, neuroblastoma cells, and that some contained debris in their cytoplasm, but it was impossible to determine whether this was the result of phagocytosis or of cell degeneration. Either view explains Landolt's obser- 
vation that cells containing debris were more numerous after deep $x$-ray therapy, although he considered that the debris had been ingested by elements which he regarded as being reticulum cells. Our photomicrographs clearly show that there are no morphological differences between the obvious tumour-cells and most of the debris-containing elements. There are, nevertheless, some cells which contain red corpuscles and polymorphs, and are thus obviously phagocytic; but whether they are tumour-cells or reticulum-cells cannot be determined.

The whole subject of the reactive proliferations of reticulum cells as found in marrow films has been discussed in detail by Nordenson (1938), who records the presence of large numbers of these elements in the vicinity of carcinomatous metastases in the marrow. It would seem, therefore, that such an appearance has not quite the pathognomonic significance that is suggested by Landolt. On the other hand, too little is known about the histological appearances of neuroblastomatous metastases in the marrow. It is, of course, possible that they are surrounded by proliferated reticulum cells, which are not sufficiently loosened from their normal attachments to be found in large numbers in material obtained by marrow puncture and suction, for as de Weerdt emphasized, "les cellules réticulo-endothéliales fixes sont exceptionelles dans les produits de ponction sternale."

There is, unfortunately, no means of differentiating, with certainty, cells which have ingested amorphous debris from those in which particulate material is present as a result of cell degeneration. In the present case the difficulty is greater than usual because no signs of phagocytosis or of cell-inclusions could be found in sections of post-mortem material. Our view is that when there is neuroblastomatous infiltration of the marrow, some tumour cells will be present in syncytial masses, while others will be more or less irregularly scattered throughout the tissue, and both may contain debris in their cytoplasm. Only if recognizable cells are present in the cytoplasm can the occurrence of phagocytosis be taken as proven.

\section{Summary}

A case of neuroblastoma of the left suprarenal gland causing Hutchison's syndrome is presented in some detail.

Radiologically the changes in the skeleton were similar to those sometimes found in the reticuloses, while sternal puncture proved to be misleading, mainly on account of the authors' ignorance of the similar cases previously recorded.

The scanty literature on the subject has been reviewed, and the nature of the so-called reticulum cells, which were found to be increased in number, has been discussed.

\section{REFERENCES}

Albertini, A. von, and Willi, H. (1938-9). Ann. paediatr., Basel, 152, 129.

Fanconi, G. (1943). Ibid., 160, 318.

Hooft, C., and Compernolle, H. (1942). Mschr. Kinderheilk., 90, 332.

Hutchison, R. (1907). Quart. J. Med., 1, 38.

Kato, K., and Wachter, H. E. (1938). J. Pediat., 12, 449.

Landolt, R. F. (1946). Helv. paediat. Acta, 1, 403.

Nordenson, N. G. (1938). Acta path. microbiol. scand., 15, 362.

Patschadji, A. R. (1941). Strahlentherapie, 70, 464.

Vogel, P., and Bassen, F. A. (1939). Amer. J. Dis. Child., 57, 245.

Weerdt, W. de (1939). Rev. belge Sci. méd., 11, 297, 337, 440. 